J. Anim. Prod. U.A.R., 5, No, 1, 43-51 (1965).

\title{
MORTALITY RATE OF CHICKS AS AFTECTED BY AGE, BREED AND MONTH OF HATCHING AT THE LIBERATION PROVINCE, U.A.R.
}

\author{
By \\ M.A. Ghany * aND SABry S.A. \\ Department of Animal Production, Faculty of Agriculture, \\ Cairo University, Giza.
}

\section{SUMMARY}

\begin{abstract}
Mortality records of nearly 190 thousand chicks bred from Forth Holland Blue and their crosses Fayoumi, Rhose Island Red, North Holland Bine and their crosses due to breed, age to twelve weeks of age and date of hatch were investigated. Results are summarized as follows :

(1) Rhode Island Red chicks showed the highest 0-12 week (1) Rhoder Holland Blue $(25.3 \%)$ then the crossbreds $(21.2 \%)$.

(2) In all groups, mortality rate declined with advancing age. The combined data show $12.4,9.4$ and 3.9 percent mortality during the $0-4,4-8$ and $8-12$ weeks of age respectively.

(3) Chicks hatched early in the season (Oct. - Dec.) Showed the least mortality. Rhode Island Red chicks were the severest affected by hot weather while the Faycumi and crossbreds were the least affected.
\end{abstract}

\section{INTRODUCHION}

The Liberation Prowince Poultry Project is one of the biggest concentra tion of poultry in U.A.R. Results secured herewith, although not comparable to those on American or European farms, are of significant importance for African and Asian projects working under similar conditions. As mortality rate during the brooding stage represents an important economic element in porltry raising, it was thought of value to investigate the mortality picture in the above project.

* Part-time technical consulkant for poultry production at the Liberation Province Organization. 


\section{REVIEW OF LTTERATURE}

Young chicks are very sensitive to chilling as shown by Seeger and Tom. have (1944), Mibailescu and Paduraru (1955) and Moustafa (1963). This is related to the lack of heat producing and conserving mechanism, (Randall (1942) and Morengand Shaffner (1951). Breed differences in resistance to special diseases (Greenwood and Blyth (1948) and Taubitz (1950) and resistance to unfavourable conditions Hutt (1938) and Fox (1951), have been demonstrated.

Crossbreeding has generally decreased mortality rate "Dickerson et al. (1950), Ragab et al. (1955), Kawahara (1959) and Nordskog and Phillips $(1960)^{\prime \prime}$. Early winter hatches survived better than summer or hot weather hatches. "Upp (1936) and Moustafa (1963)".

\section{MATERIALS AND METHODS.}

Records kept on mortality for three hatching seasons (1958/1959 through 1960/1961) were available for this study. Those included 188, 657 chicks belonging to Rhode Island Red (R. I. R.), North Holland Blue (N. H.B.), Fayoumi (F.) and orosses of foreigen cockerels and Fayoumi females (C.) (Table 1). Chicks wore hatched weekly at two stations and reared on floor in compartmental brooder houses, with about 500 chicks per compartment. Electric heaters were used and adequate rations were fed, (Table 2). When six weeks of age, the chicks were transferred to new quarters with only night heating as necessary.

TABLE 1.-Total aumber of hatching chicks having complete mortality records from 0-12 weeks of age according to breeds and farms.

\begin{tabular}{l|l|l|l|l|l}
\hline Breed & R.I.R. & N. H. B. & F. & C. & Total \\
\hline Parm & & & & & \\
\hline & & & & & \\
Omm Saber . & 12691 & 10535 & 24225 & 3962 & 51413 \\
Total . . & 33570 & 41244 & 86835 & 25008 & 188657 \\
\hline
\end{tabular}


TABLE 2.- The composition of chick and laying ration fed usualy during the three seasons studied.

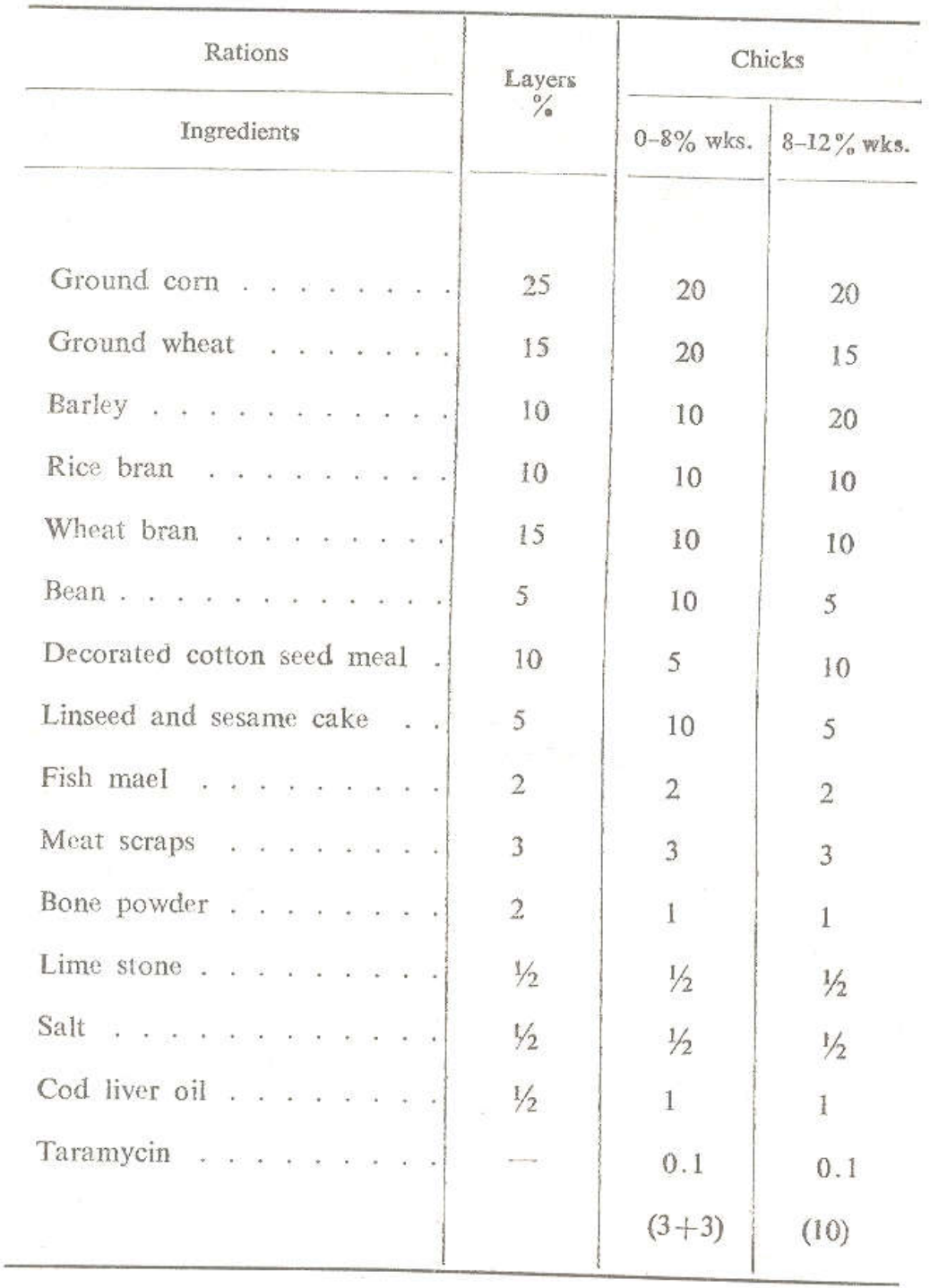

Barseem (Trifolium Alexandrinum) was offered at mid meals. 


\section{RESULTS AND DISCUSSIONS.}

\section{A.-Age and Breeds:}

As shown in Table (3) the highest mortality rate for all breeds occured withen the first four weeks of life. Death rate tended 'o decrease considerably thereafter. This confirms previous reports and earlier explanation of this observation. It als means that special care should be taken when managing young chicks to avoid such high losses. Feeding and heating elements need to be carefully checked for this purpose, with adequate hygenic measures.

The R.I.R. chicks showed the poorest vitality. This was mainly due to the extension of the high rate of mortality after the first four weeks of life. The crossbreds showed the lowest mortality in this period, while the N.H.B. and $\mathrm{F}$. chicks were intermediate. It is worth noting that the early mortality in Fayoumi and its crossbreds was higher than that in the pure foreign breeds. This may be due to chance or to some other faciors worthy of investigation. The high mortality of the R.I.R. chicks during hot weather ought to be considered. It is our opinion that breed's responses to climatic as well as other environmental conoitions in Egypt need further experimentation.

Early findings of Ragab et al. (1957), Amer et al. (1957) and Rizk ind El-Ibiary (1960) favoured crossbreeding but found no one breed consistently superior under the local experimental conditions.

TABLE 3.-Number of hatching chicks in the different breeds amd crosses and their mortality percentage from $0-4,4-8,8-12$

and $0-12$ weeks of age.

\begin{tabular}{|c|c|c|c|c|c|}
\hline \multirow{2}{*}{ Breeds } & \multirow{2}{*}{$\begin{array}{l}\text { Chicks } \\
\text { No. }\end{array}$} & \multicolumn{3}{|c|}{ Ages (weeks) } & \multirow{2}{*}{$\begin{array}{c}\text { Total } \\
0-12\end{array}$} \\
\hline & & $0-4$ & $4-8$ & $8-12$ & \\
\hline R.I.R. & 35570 & 11.6 & 11.4 & 5.1 & 28.1 \\
\hline N.H.B. & 42144 & 10.5 & 9.6 & 5.2 & 25.3 \\
\hline F. & 86885 & 13.7 & 9.2 & 3.3 & 26.2 \\
\hline C. & 25008 & 12.2 & 6.9 & 2.1 & 21.2 \\
\hline Total average. & 188657 & 12.4 & 9.4 & 3.9 & 25.7 \\
\hline
\end{tabular}




\section{B.-Month of hatching :}

Table 4 and Figure 1 show the mortality xate for the different monthly hatchs at 4-week intervals. It is generally observed that chicks hatched during the first three months of the season i.e. October, November and December have lower mortality than those hatched later. The only feasable explanation for this may be linked with better housing and infection control during cooler weather plus succulant green feed (Trifolium Alexandrinum). The cold nights of January and February aro also responsible for the high losses experienced within the winter period especially as the Liberation project, lies close to the western desert.

It can be observed from the above illustration that after four weeks of age, the Fayoumi and its crosses withstand hot weather far better than either Rhode Island Red or North Holland Blues. This may be due to some adaptive traits of the Fayoumi to hot weather, although more extensive work is needed to draw substantial conclusions in this respect.

TABLE 4.- Mondhy and total number of hatching chicles from all sources and their mortality percentage from $0-4,4-8,8-12$ and $0-12$ weaks of age.

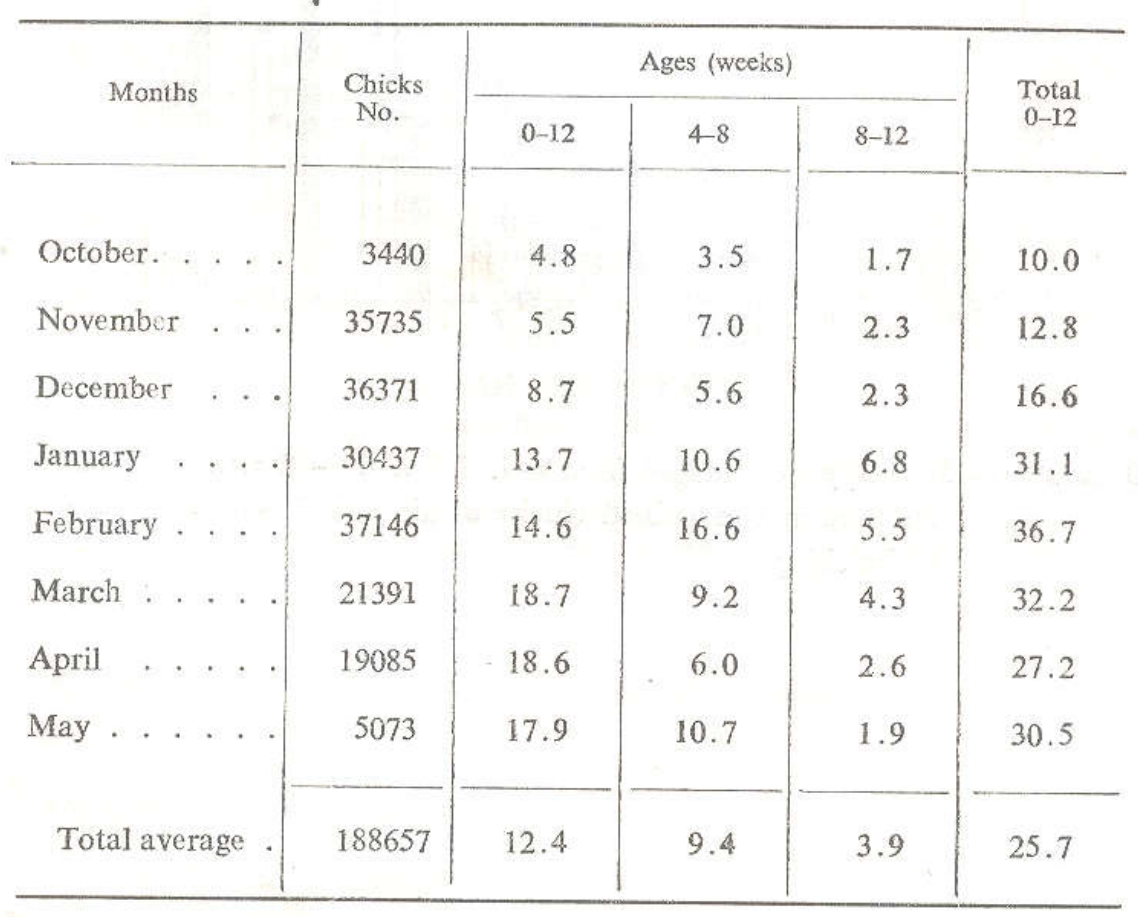




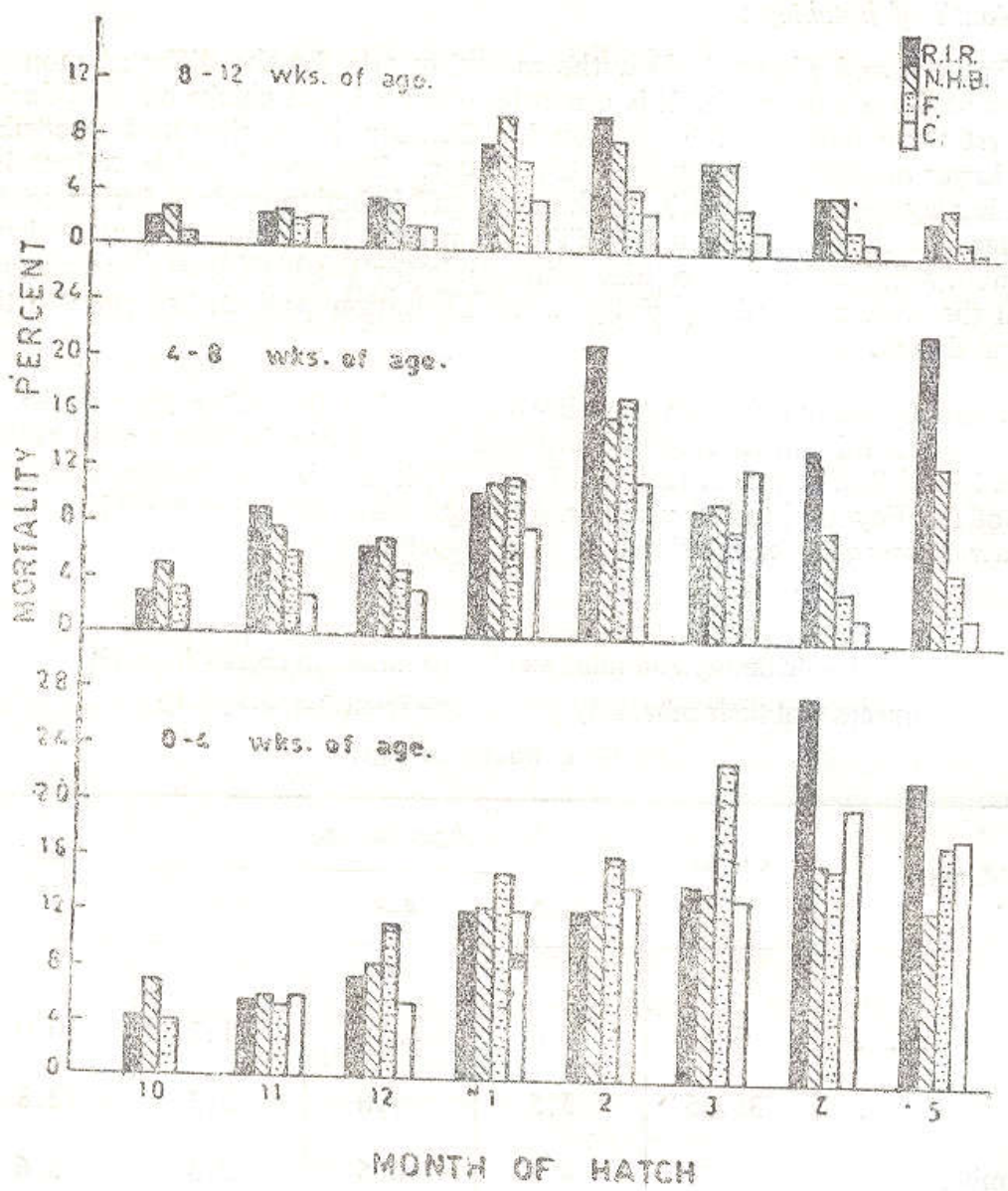

Diagrax 1.-Mortality percentages from $0-4,4-8$ and $8-12$ weeks of age for pure and crossbred chicks within the different months of hatching. 
It is evident from the preceding results that the $25.7 \%$ chick mortality from 0-12 weeks of age is much too high. With the future expantion of broiler industry and intensive poultry farming on the national level, reducing such a huge percent should be given the greatest concern. Many managerial aspects including housing, feeding and competing diseases and parasites must be considered. If proper environmental facilities cannot be maintained, it is recommended that the projects be confined to the available suitable facilities. It is also felt that more work is needed for developing more suitable chicks under cur climatic conditions. The hot weather of summer creates many problems to be solved. Unless we do our best to find proper solutions for the above problems, poultry production will always be limited.

\section{ACKNOWLEDGMENTS}

The authors are deeply grateful to Prof. Dr. M.T. Ragab for the interest, guidance, and help they recieved from him during the coarse of this work.

Also many thanks are due to the General Director of the Organization Mr. Fouad Ali, and the poultry Staff for their kind encouragment and assistance.

\section{REFERENCES}

Asnex, M.F., H.M, El- Mbiary, S.S. Khishin and H.F. Issawi, (1957). A comparitive study of Egyptian strains of chickens and three standard breeds imported from Holland. 1- Fertility, hatchability and chick mortality. Alexandria J. of Agric. Res., 2; 2 ; No. 2 : 103-121.

Upp. C. W. (1936) . Comparison of management methods for chicks, layers and breeding hens. Louisiana Bull. No. 275. September 1936.

Dickerson, G.E., Q..B. Kinder, W.F. Krueger, and H.L. Kempster (1950). Heterosis from crossbreeding and from out breeding. Poultry Sci., $29: 756$.

Box, T.W. (1951). Studies on heat tolerance in the domestic fowl. Poultry Sci., $30: 477-483$.

Greenwood, A.W., and J.S.S. Blyth, (1948). The problem of pullet mortality. Off. Rep. 8th. World's Poult. Congr. (Copenhagen). 1 : 687-691.

Fwtt, I.B. (1938). Genetic of the fowl. VII. Breed differences in succeptibility to extreme heat. Poultry Sci, $17: 454-462$.

Eawahara, T. (1959). Influence of heterosis on viability of the F1 hybrids between two breeds of the domestic fow1. W.P.S.J. 17, No. J. 17, No. 1,p. 42. 1961.

Mihsilesca, N., and A. Paduraru, (1955). The growth of Rhode Island chick8 from hatching to six months of age. Anal. Inst. Cere. Zooteh.l $13: 387-397$. (A.B.A. $25: 87$ ). 
Moreng, R.E., and C.S. Shaffiner, (1951). Lithal internal temperatures for the chickens from fertile egg to mature bird. Poultry Sci., $30: 255$. 266.

Monstafa, M.B. El-Din, (1963). Adaptability of some foreign breeds of poultry (Chickens) and their crosses under Egyptian environmental conditions. M.Sc. Thesis, Univ. of Cairo.

Nordskeg, A.W., and K. W. Phllips, (1960). Heterosis in poultry 5 - Reciprocal crosses involving Leghorns, heavy breeds and Fayoumi. Poultry Sci., $39: 257-263$.

Ragab, M.T., Asker A.A. and M. with White Leghorns. Poultry Sc., $42:$ p. 326.

Ragah, M.T., A.A. Asker, and E. Samak, (1957). Effect of crossing Fayoumi fowls with light Sussex and R.I. Rs. Bull. Fac. Agric., Cairo Univ. No. 95

Randa1!, E.C. (1942). Factors influencing the temperature regulation of birds. Amer. J. Physiology, 139:56-63.

Rizk X. and El-Ebbiary H.M., (1960). Body size, feeding efficiency and mortality rate in 16 weeks old Fayoumi chicks. Alex. J. Agric. Res. Bull. Vol. 8 No. 1.

Seegr, K.C., and A.E. Tomhave, (1944). Causes of mortality in four successive flocks of broilers at the substation. Del. Agric. Exp. Sta., No. $249: 23$ pp. (A.B.A. $13: 162$ ).

Tambitz, K. (1950). The occurrence of chronic pullorum infection in different poultry breeds. (A.B.A. 21:81).

(Printed in 1987) 


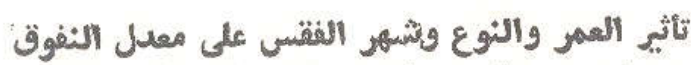

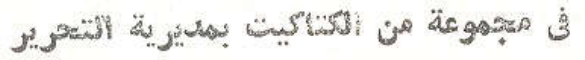

\section{vatin!}

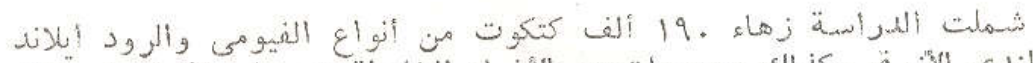

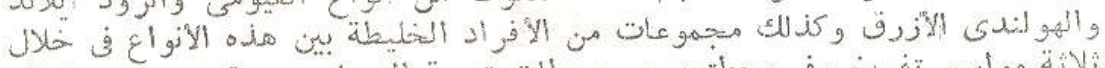

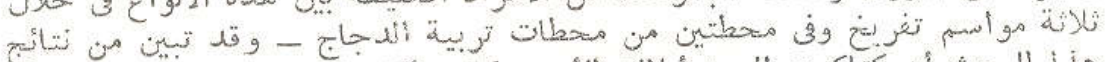

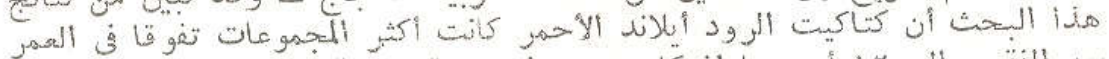

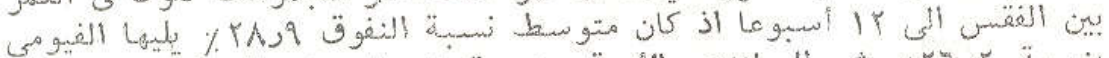

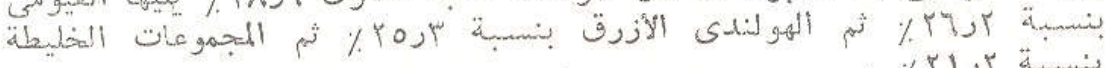

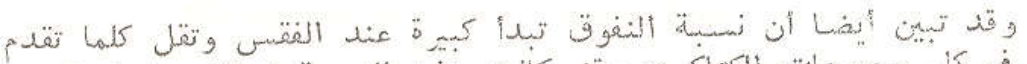

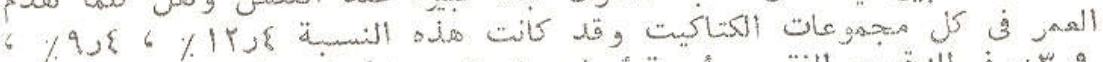

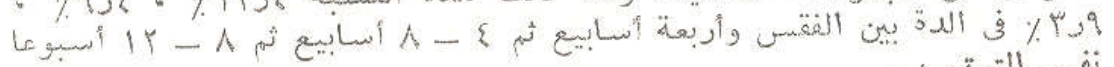

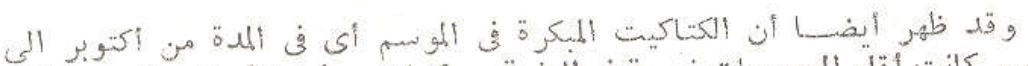

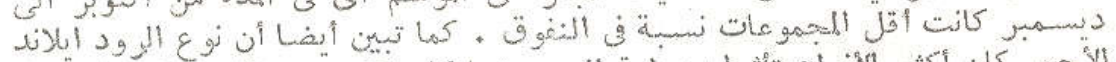

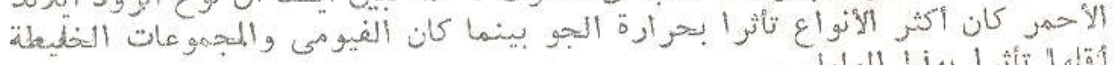

